\title{
THE ECOLOGY OF ELEVATIONAL POSITIONS IN PLANTS: DROUGHT RESISTANCE IN FIVE MONTANE PINE SPECIES IN SOUTHEASTERN ARIZONA ${ }^{1}$
}

\author{
Andrew M. Barton ${ }^{2}$ And JAmes A. TeEri \\ Department of Biology, University of Michigan, Ann Arbor, Michigan 48109
}

\begin{abstract}
We subjected seedlings of five pine species from the Chiricahua Mountains, Arizona to drought in the greenhouse to assess the relationships among elevational position, drought resistance, and biomass allocation. In comparison with upper elevation species, lower elevation species survived longer and experienced less depression of photosynthesis in response to the imposed drought. During the last week of the 29-d drought, internal water potential decreased little in lower elevation species but dropped precipitously in upper elevation species. Thus, relative drought resistance and elevational position of these pines seem associated with the ability of seedlings to survive drought by maintaining favorable plant water potential. Lower elevation and more drought-resistant species allocated less biomass to roots than did other species, a fact suggesting, contrary to assumptions of recent plant community models, that biomass allocation was unimportant in species differences in drought resistance.
\end{abstract}

Within a region, plant species tend to occur consistently at the same relative positions along environmental gradients (Daubenmire, 1943b; Grime, 1979; Tilman, 1988). This consistency suggests that, rather than developing unique explanations for every site, we can attribute the control of local plant distributions and thus spatial changes in species composition to a common set of ecological processes.

Elevational gradients provide conspicuous examples of consistent relative positions of plant species. In semiarid zones, elevational positions are potentially controlled by many variables correlated with elevation (Shreve, 1915; Daubenmire, 1943b). Through a series of field studies, Barton (in press) examined the role of several of these variables, including moisture availability (i.e., drought), fire, and competition for light. In this paper, we describe complementary greenhouse studies of the importance of moisture availability, which increases with altitude (Shreve, 1915; Pearson, 1931; Wright, 1966; Barton, 1991). To examine the role of this gradient in controlling plant elevational positions, we tested the hypothesis that relative drought resistance (ability to survive and to function under drought conditions, Levitt, 1980) is correlated with the relative elevational positions of five pine species in the Chiricahua Mountains in southeastern Arizona. Relative drought resistance was assessed by comparing spe-

\footnotetext{
' Received for publication 20 February 1992; revision accepted 18 September 1992.

The authors thank B. Barnes, B. Fogel, D. Goldberg, B. Rathcke, S. Sloane, and D. Zak for substantial help on the manuscript; B. Swanson and $S$. Sherman for assistance in harvesting plants and entering data; the Matthaei Botanical Gardens and the Department of Biology of the University of Michigan for greenhouse space and supplies; the Southwestern Research Station (American Museum of Natural History) for help and hospitality; Coronado National Forest for permission to collect seeds; and K. Guire and K. Welch at the Statistics Research Laboratory of the University of Michigan for assistance with statistical analyses. AMB especially thanks $D$. Goldberg, chair of his dissertation committee, for advice throughout this project.

${ }^{2}$ Author for correspondence, current address: Center for Evolutionary Ecology, T. H. Morgan School of Biological Sciences, University of Kentucky, Lexington, KY 40506.
}

cies for both gas exchange and survival responses to a drought imposed in a greenhouse.

We also evaluated the results in the context of mechanisms of drought resistance (see Levitt, 1980). We examined whether species differences in drought resistance resulted from 1) avoidance of drought by maintenance of favorable levels of plant water potential or 2) tolerance of drought by continued physiological activity in the presence of decreasing plant water potential. We also tested whether drought-resistant species allocated more biomass to belowground vs. aboveground parts than did less drought-resistant species. Allocation to these parts may have important consequences for drought avoidance and for plant distribution along gradients of soil resources (such as soil moisture) and light, which characterize many elevational gradients (Daubenmire, 1943b; Barton, 1991). Allocation is also a central element of recent theories of plant community structure (e.g., Grime, 1979; Tilman, 1988; Smith and Huston, 1989).

\section{MATERIALS AND METHODS}

Study site and species - The Chiricahua Mountains, located in southeastern Arizona $\left(31^{\circ} 52^{\prime} \mathrm{N}, 109^{\circ} 15^{\prime} \mathrm{W}\right)$, are a prominent part of the Mexican Highland Section of the Basin and Range Geologic Province (Fenneman, 1931). They extend southeast to northwest for about $80 \mathrm{~km}$ and rise from 1,100 to 1,300 -m basins to a maximum altitude of about 3,000 $\mathrm{m}$ at Chiricahua Peak. Most soils in these mountains are derived from volcanic rhyolites and monzonites deposited in the early- to mid-Miocene, although, at lower elevations in several major eastern drainages, pre-tertiary sedimentary parent rock predominates (Marjanieni, 1969; Drewes and Williams, 1973).

The climate of the region is arid to semiarid with two wet seasons, one between July and September, when greater than $50 \%$ of total precipitation falls, and the second between December and March. A pronounced dry season usually occurs between the final winter storms in March or April and the onset of the rainy season in July (Sellers, Hill, and Sanderson-Rae, 1985). At the Southwestern Research Station, at about $1,650 \mathrm{~m}$ altitude in these moun- 
tains, mean annual rainfall is $506 \mathrm{~mm}$, and mean annual temperature $12.5 \mathrm{C}$.

Precipitation increases and air temperature decreases with increasing elevation in southeastern Arizona. For stations near the Mule Mountains, for example, Wentworth (1981) found an increase in summer precipitation (May-October) of $190 \mathrm{~mm}$ and a decrease in mean July temperature of $7.3 \mathrm{C}$ for every $1,000 \mathrm{~m}$ elevation increase, results similar to those of other studies (Shreve, 1915; Pearson, 1931).

The nine pine species occurring in southern Arizona (Critchfield and Little, 1966; Bailey and Hawksworth, 1983) occupy consistent relative elevational positions in the region, although not all nine occur in all mountain ranges (Shreve, 1915; Martin and Fletcher, 1943; Wallmo, 1955; Whittaker and Niering, 1964, 1965; Barton, 1991; for a possible exception, see Peloquin, 1971). Of these nine pine species, seven occur in the Chiricahua Mountains, and we describe experiments on five (nomenclature follows Bailey and Hawksworth, 1983). From lower to higher elevation, they are Pinus discolor Bailey and Hawksw. (1,500-2,000 m), P. leiophylla var. chihuahuana (Engelm.) Shaw (1,600-2,100 m), P. engelmannii Carr (1,900-2,200 m), P. ponderosa var. scopulorum Engelm. $(2,400-3,000 \mathrm{~m})$, and $P$. strobiformis Engelm. (2,450$3,000 \mathrm{~m})$. We do not present the greenhouse data for $P$. arizonica Engelm. because sample sizes were insufficient, and we did not study $P$. edulis because it is uncommon and occurs only in the extreme northern part of the mountain range. Of the five species studied here, all but $P$. ponderosa are of Sierra Madrean affiliation (Critchfield and Little, 1966), and their physiological ecology is poorly understood.

Greenhouse methods and experimental design-Seeds were collected in October to December 1986 from at least ten widely separated trees of each species, except for $P$. ponderosa, of which only four trees were sampled. Seeds were cold stratified for at least 2 mo and germinated in Metromix (W. R. Grace and Co.) at the University of Michigan Matthaei Botanical Gardens, where all subsequent greenhouse research was carried out. After emergence, seedlings were transplanted into $50.8 \times 29.9-\mathrm{cm}$ trays containing 38 conical permanently fixed containers, each $15.2 \mathrm{~cm}$ deep, $5.33 \mathrm{~cm}$ in diameter at the top, and $1.9 \mathrm{~cm}$ in diameter at the bottom. Each seedling was transplanted into one cone containing equal parts unwashed sand, redwood bark, sphagnum peat, and perlite.

Before imposing water stress, we grew the plants from 23 October 1987 to 11 February 1988 under nonlimiting soil moisture conditions. Mercury vapor lights supplemented ambient greenhouse sunlight. Photosynthetic photon flux density reaching seedlings ranged from about $450 \mu$ moles $\cdot \mathrm{m}^{-2} \cdot \mathrm{sec}^{-1}$ under edges of the artificial lights to about $850 \mu \mathrm{moles} \cdot \mathrm{m}^{-2} \cdot \mathrm{sec}^{-1}$ under centers. Plants were watered every 1 or $2 \mathrm{~d}$, depending on greenhouse temperature and humidity. Soluble Peter's Balanced Fertilizer (20-20-20 at 300 parts per million) was added to this water once a week. Seedling mortality was high. To avoid excessive transplanting to replace dead plants, we grew each species in one or two monoculture trays rather than in a fully randomized design with multispecies trays. We sought to avoid lab bench position effects by rotating the positions of trays once a week prior to and twice a week during the drought treatment.

To drought-harden the plants, we withheld water from all seedlings for two 5-d periods between 11 and 21 February; each drying period was terminated with watering to saturation. The imposed drought began on 21 February. Plant microclimate at midday during the drought treatment was typically as follows: air temperature at plant height was $23-28 \mathrm{C}$, relative humidity at plant height was $34 \%-49 \%$, and soil temperature at $7 \mathrm{~cm}$ depth was $24-$ $29 \mathrm{C}$.

Just prior to imposing drought, we divided the seedlings into three groups: plants subject to drought and observed until death, plants subject to drought and sampled for gas exchange and water potential, and control plants not subject to drought and sampled for gas exchange and water potential. In the first group, we observed seedlings daily until "death," defined as the complete loss of turgor or loss of green color. In separate tests with P. strobiformis, seedlings did not recover from a complete loss of turgor. After death, each seedling was separated into roots, stem, and needles for drying and weighing by picking through soil with forceps. Percentage soil moisture was determined gravimetrically for the remaining soil. Sample sizes for this group ranged from 17 to 30 seedlings per species because of differences among species in the number of seeds harvested and in the germination and preexperiment survival rates.

From the second group of water-stressed plants, three seedlings of each species were sampled at each of seven dates spread over $29 \mathrm{~d}$. At each sampling period, between 0930 and $1130 \mathrm{hr}$, each randomly selected seedling was severed at ground level and immediately measured for net carbon dioxide $\left(\mathrm{CO}_{2}\right)$ uptake for $1 \mathrm{~min}$ in an ADC model LCA-2 Infrared Gas Analyzer with conifer cuvette at a photosynthetic photon flux density of about 800 $\mu$ moles $\cdot \mathrm{m}^{-2} \cdot \mathrm{sec}^{-1}$. Whole seedling water potential was subsequently measured in a pressure bomb. We also determined percentage soil moisture gravimetrically and the dry weight of roots, stems, and needles for each seedling. On 7 March, the same measurements were made on five control seedlings for each species, which were supplemented with water as needed to avoid water-stress.

Statistical analyses-As expected, for all species net $\mathrm{CO}_{2}$ uptake, plant water potential, and percentage soil moisture decreased from plants sampled at the beginning to those sampled at the end of the 29-d drying period (see Figs. 2-6). For species able to maintain these processes at favorable levels, the slope of these decreases should be less than for other species without such ability. Thus, we based the analyses on the assumption that lower slopes reflected greater drought resistance. We used a multiple regression model with the response variable $\left(\mathrm{CO}_{2}\right.$ uptake, plant water potential, or soil moisture) as the dependent variable and with three continuous independent variables: 1) days since watering (or its analogs, percentage soil moisture or plant water potential); 2) elevational position of species, ranging continuously from one (lowest elevation) to five (highest elevation); and 3) interaction term of days since watering and elevational position. The interaction term represents the relationship between elevational position and the slope of decreases in $\mathrm{CO}_{2}$ uptake, plant 

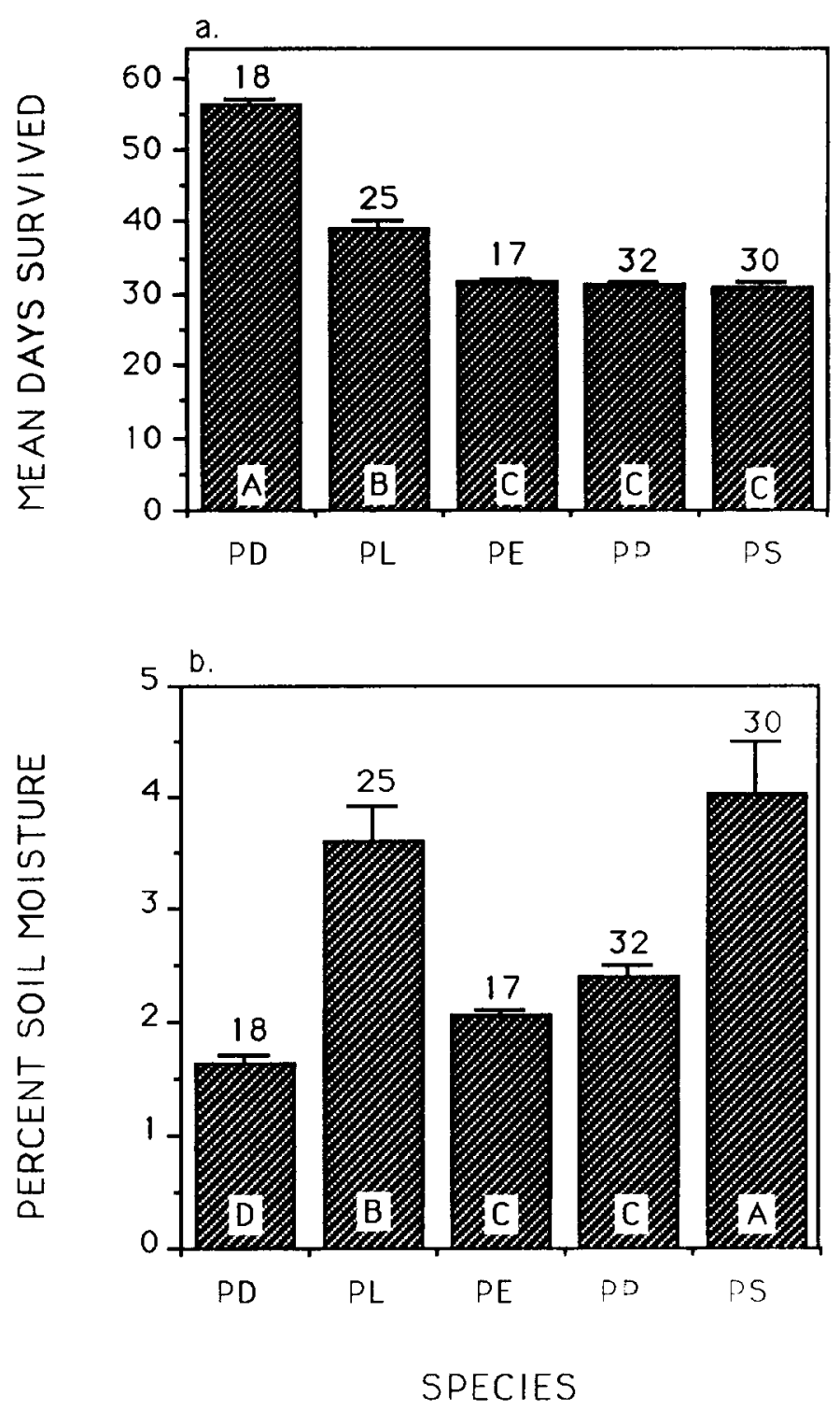

Fig. 1 (two panels). Mean number of days survived from last watering (a) and mean percentage soil moisture at death for individuals of each of five pine species (b). Sample sizes are given at the tops of standard error bars. Means that do not share the same letter are significantly different $(P<0.05, \mathrm{C}$ method; Day and Quinn, 1989). $\mathrm{PD}=P$. discolor; $\mathrm{PL}=P$. leiophylla $; \mathrm{PE}=P$. engelmannit $\mathbf{P P}=P$. ponderosa $; \mathrm{PS}=P$. strobiformis. Elevational position of pines increases from left to right.

water potential, and percentage soil moisture. We used the one-tailed probability value associated with the interaction term to test the hypothesis that slope decreases (i.e., drought resistance increases) from high to low elevation species. When slopes are negative (e.g., days since watering), the interaction term should be negative, and when they are positive (e.g., soil moisture), it should be positive. Although control plants (those receiving water) were measured on the 15 th day after water was withheld from treatment plants, these data were coded as day zero (i.e., zero days of drying) for the foregoing analyses and for the figures.

To examine the extent to which biomass allocation led to differences in drought resistance in young seedlings, we

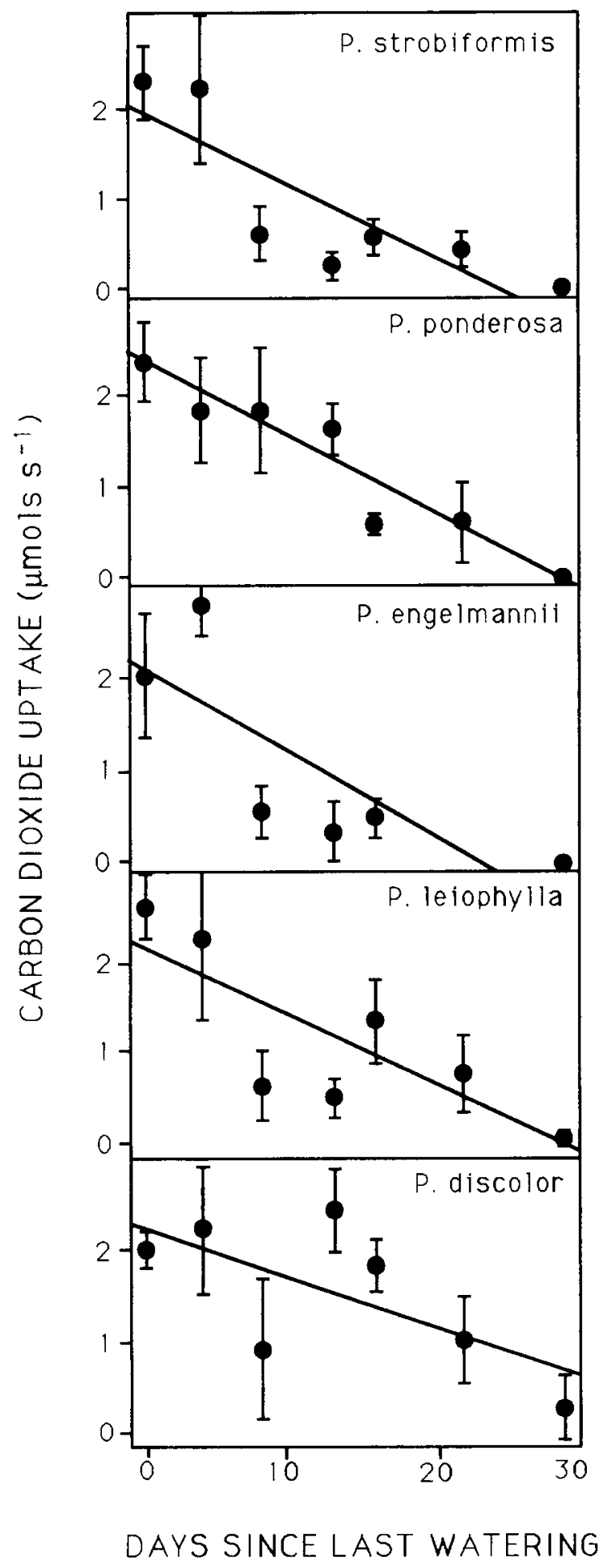

Fig. 2 (five panels). Mean carbon dioxide uptake per seedling for five pine species over 29 d during which water was withheld. Bars are standard errors. Sample size is two for day 4 for $P$. discolor and three for all others. Although control plants (those receiving water) were measured on the 15 th day after water was withheld from treatment plants, these data are given as day 0 (i.e., 0 days of drying). Statistical results are given in Table 1. Elevational position of species increases from lower to upper frames. 


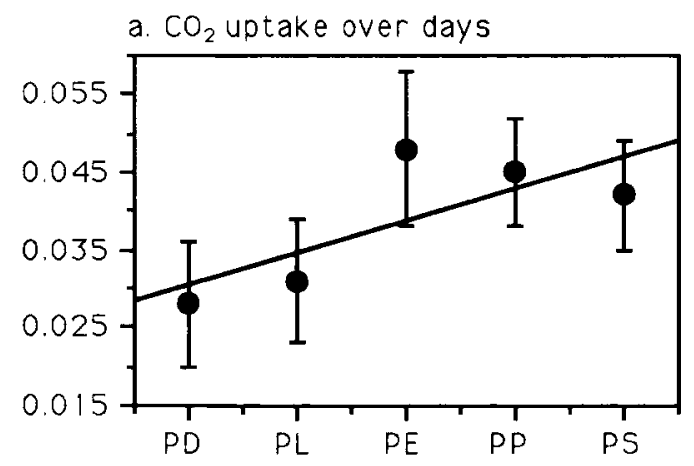

b. $\mathrm{CO}_{2}$ uptake over plant water potential

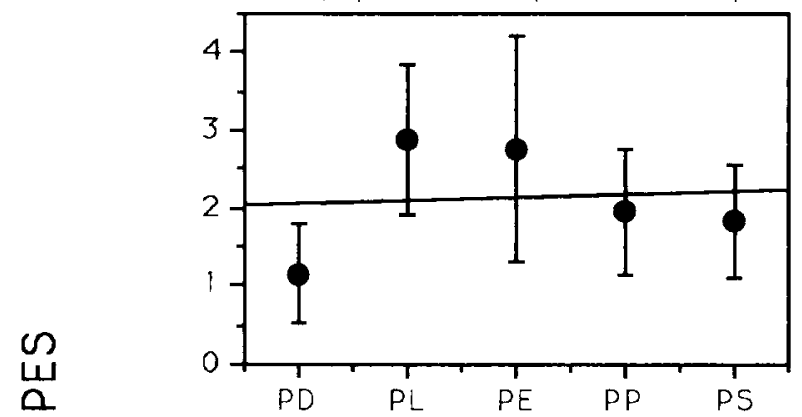

c. Plant water potential over days

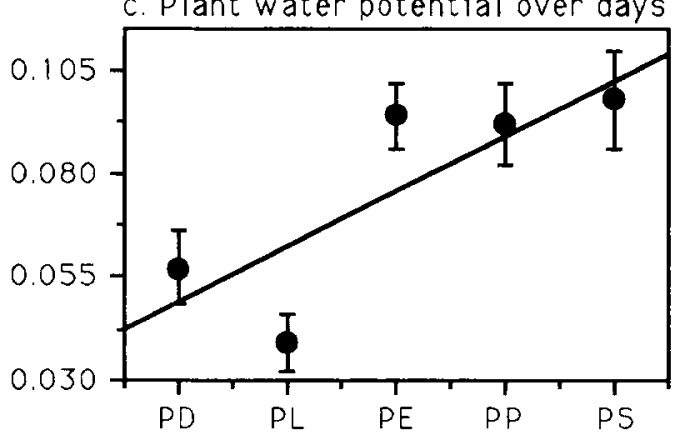

d. Soll moisture over days

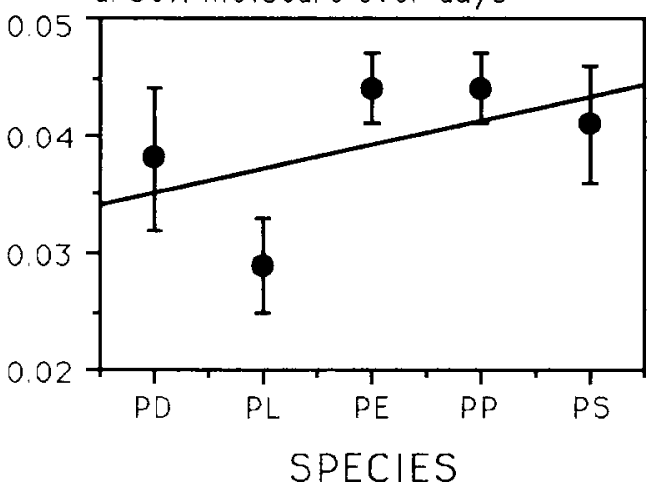

Fig. 3 (four panels). For five pine species, slopes (with standard error bars) from simple linear regressions (from the gas exchange experiment) of (a) carbon dioxide uptake per plant over days, (b) carbon dioxide uptake per plant over plant water potential, (c) plant water potential over days, and (d) percentage soil moisture over days. Each slope is the result of the best linear fit after transformation (log or square root). Each slope is significantly different from zero at at least $P<0.01$, most at $P$ $<0.001 . F$-values given for each frame are for interactions from Table 3.1. Significant interactions indicate that the steepness of the slope increases with elevational position of pine species (i.e., lower elevation compared biomass allocation patterns of the five species at one age only $(4.5-5 \mathrm{mo})$. This violates the recommendation of Strauss and Ledig (1985) that, because allocation changes in a species-specific manner as a plant grows, species allocation patterns should be compared by means of allometric constants. However, the pine species used in this experiment face their first summer drought at approximately the same age (but not the same size). Thus, comparing allocation patterns among species at this same age seems not only reasonable, but especially relevant to hypotheses connecting allocation, drought resistance, and elevational distribution.

When possible, we used parametric analyses, transforming the raw data where needed to meet assumptions of homoscedasticity and normality of residuals. When data could not be transformed to meet these assumptions approximately (species comparisons of number of days survived, percentage soil moisture at death, percentage allocation, and root and total mass), we used nonparametric analogs. Because the residuals in most of the multiple comparisons were non-normally distributed and unequal in variance even after transformation, we employed the C method for these analyses (Day and Quinn, 1989).

\section{RESULTS}

Drought resistance: survival-As expected, lower elevation species survived longer than did higher elevation species during the drought treatment. The mean number of days survived differed significantly among the five pine species (Kruskal-Wallis test, $\mathrm{df}=4, \mathrm{H}=70.42, P<$ 0.0001 ; Fig. 1a). Seedlings of $P$. discolor, the lowest elevation species, survived longer than did those of the second lowest elevation species, $P$. leiophylla, both of which survived longer than did all three species from higher elevations $(P<0.05$; Fig. 1a). Closely paralleling these data, date of first death ranged from $23 \mathrm{~d}$ after cessation of watering for the highest elevation species to $51 \mathrm{~d}$ for $P$. discolor. The death date of the last seedling for each species ranged from $36 \mathrm{~d}$ for the next-to-the-highest elevation species to $60 \mathrm{~d}$ for $P$. discolor. Survival of $P$. discolor was especially impressive: the first seedlings of this species did not die until the last seedlings of the other four species had all died.

The five species also differed significantly in percentage soil moisture at the time of death during the drought treatment (Kruskal-Wallis test, df $=4, \mathrm{H}=73, P<$ 0.0001 ; Fig. 1 b). As expected, mean percentage soil moisture at death was smallest for $P$. discolor and greatest for $P$. strobiformis. All but one species fit between these extremes in accordance with their elevational position (Fig. 1b). In contrast to its long survival time during the drought, $P$. leiophylla died at the relatively high soil moisture levels characteristic of higher elevation species (Fig. 1b).

species are more resistant to the imposed drought than are higher elevation species). $\mathrm{PD}=P$. discolor; $\mathrm{PL}=P$. leiophylla $; \mathrm{PE}=P$. engelmannil; $\mathbf{P P}=P$. ponderosa $; \mathrm{PS}=P$. strobiformis. Elevational position of species increases from left to right. 
TABLE 1. F-statistics from multiple regressions with response variable (CO, uptake, plant water potential, or soil moisture) as dependent variable and three continuous independent variables: days since watering (or its analogs, soil moisture or plant water potential), elevational position of species, ranging continuously from one (lowest elevation) to five (highest elevation), and the interaction term. Significant interactions indicate that slopes of these relationships become steeper from lower to higher elevation species (i.e., lower elevation species are more drought resistant). Although control plants (those receiving water) were measured on the 15th day after water was withheld from treatment plants, these data are given as day 0 (i.e., 0 days of drying)

\begin{tabular}{|c|c|c|c|c|c|c|c|c|c|}
\hline & \multicolumn{3}{|c|}{ Days since watering ${ }^{a}$} & \multicolumn{3}{|c|}{ Percent soil moisture } & \multicolumn{3}{|c|}{ Plant water potential ${ }^{2}$} \\
\hline & Days & Elev & Inter & $\mathrm{Sm}$ & Elev & Inter & Pwp & Elev & Inter \\
\hline \multicolumn{10}{|l|}{$\mathrm{CO}_{2}$ uptake $^{\mathrm{b}}$} \\
\hline Per plant & $8.64^{* *}$ & 0.09 & $2.76^{*}$ & $3.84^{*}$ & $4.08^{*}$ & 0.66 & $5.38^{*}$ & 0.59 & 0.01 \\
\hline Per needle cg & $5.66^{* *}$ & 0.18 & $2.76^{*}$ & $3.69^{*}$ & 1.44 & 0.29 & $3.50^{*}$ & 0.66 & 0.01 \\
\hline$D f^{c}$ & & 1,107 & & & 1,82 & & & 1,86 & \\
\hline \multicolumn{10}{|c|}{ Plant water potential ${ }^{a}$} \\
\hline \multicolumn{10}{|c|}{ Percent soil moisture ${ }^{a}$} \\
\hline Per plant pot & $41.09^{* * *}$ & 0.00 & 0.58 & & & & & & \\
\hline $\mathrm{Df}^{\mathrm{c}}$ & & 1,83 & & & & & & & \\
\hline
\end{tabular}

${ }^{\text {a }}$ Day = days since watering; Elev = elevational rank of species; Inter $=$ interaction; $\mathrm{Sm}=$ percent soil moisture; Pwp = plant water potential.

- To meet the assumptions of parametric analyses, these transformed dependent variables were used: $\log \left(\mathrm{CO}_{2}\right.$ uptake), $\log$ (water potential), square root (percent soil moisture), log (total plant mass), and arc sin (percent allocation to roots).

c Degrees of freedom for each of the three tests included in the indicated model.

${ }^{*} P<0.05 ;{ }^{* *} P<0.01 ;{ }^{* * *} P<0.001$; otherwise $P>0.05$; two-tailed probabilities for elevational position and one-tailed for all others (see Materials and Methods: Statistical analyses).

Drought resistance: gas exchange and photosynthesisWhole plant photosynthetic responses to the imposed drought support the contention that relative drought resistance increases from higher to lower elevation pine species. Carbon dioxide uptake of the three higher elevation species decreased to less than $25 \%$ of well-watered controls (day zero in Fig. 2) by the 16th day of drought and to zero by day 29 . In contrast, the lower two species showed levels above $50 \%$ of controls on day 16 and still exhibited positive $\mathrm{CO}_{2}$ gain on day 29 (Fig. 2). Accordingly, the interaction term between elevational position and days since watering was negative and significant (i.e., slopes decreased from higher to lower elevation species; Table 1; Fig. 3a), indicating increasing resistance to drought from higher to lower elevation species. When soil moisture, instead of days, was used as the independent variable, the interaction term was not significant (Table 1), however. Soil moisture was measured on only six of the seven dates, which may account for the different outcome.

We examined the extent to which differences among species in drought tolerance (continued physiological activity in the presence of increased water stress, Levitt, 1980) led to differences in drought resistance by testing for a relationship between the elevational position of species and the slopes of $\mathrm{CO}_{2}$ uptake as plant water potential decreased during the drought (i.e., interaction term; see Materials and Methods: Statistical analyses). To avoid unwarranted extrapolation along the independent variable, we confined comparisons to the range of plant water potentials common to all species $(>-2.5 \mathrm{MPa})$. Although species differed somewhat in this ability at low water potentials (around $-2 \mathrm{MPa}$; Fig. 4), overall, the ability to maintain $\mathrm{CO}_{2}$ uptake despite decreasing water potential was unrelated to elevational position (Table 1; Fig. 3b).

In the three previous sets of analyses, $\mathrm{CO}_{2}$ uptake was expressed on a per-plant basis. Using $\mathrm{CO}_{2}$ uptake per unit total biomass or per unit needle mass modified the results very little (Table 1). For $\mathrm{CO}_{2}$ uptake per unit total biomass over days, the $P$-value for the interaction term did increase from smaller than 0.05 to 0.07 (Table 1).

The main differences among species in the responses of plant water potential to the drought appeared on day 29 (Fig. 5). Whereas the two lower elevation species experienced no decrease $(P$. leiophylla) or only a moderate decrease $(P$. discolor), the water potential of the three upper elevation species dropped precipitously, in most cases to the minimum detectable by the pressure bomb $(-4 \mathrm{MPa})$. These differences show up as a strong significant relationship between slope and elevational position (interaction term negative; Table 1; Fig. 3c). A significant decrease in slope with decreasing elevational position of species was also found when percentage soil moisture instead of days was used as the independent variable (Table 1).

Percentage soil moisture seemed to decrease over time similarly for all species, and the slope of decrease was unrelated to elevational position of species (Table 1; Fig. $3 d$ ), although percentage soil moisture seemed unusually high in P. leiophylla containers at the end of the experiment (Fig. 6).

Differences in biomass allocation among species-To assess differences among species in biomass allocation and in absolute biomass, we used data from the plants harvested during the gas exchange measurements, because plants were sampled at equivalent ages for each species. Species differences in biomass allocation, as well as absolute biomass, in the survival experiment were very similar to those in the gas exchange experiment and are not presented.

Biomass allocation changed very little during the drought. Only $P$. discolor, the most drought-resistant species, exhibited a shift in allocation to roots and away from aboveground organs. This change was significant for roots 


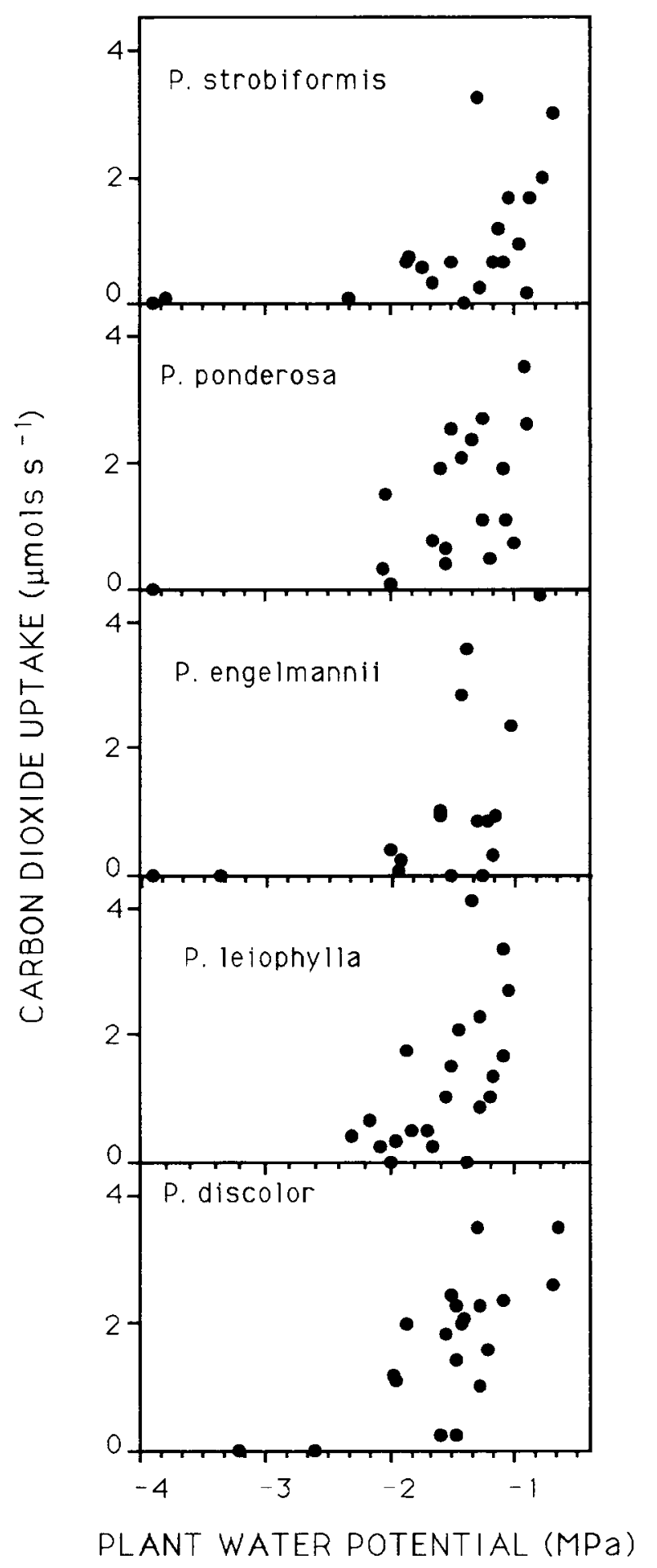

Fig. 4 (five panels). Carbon dioxide uptake vs. plant water potential for five pine species over $29 \mathrm{~d}$ during which water was witheld. Each point represents one destructively sampled seedling. Statistical results are given in Table 1. Elevational position increases from lower to upper frames.

$(N=21, r=0.43, P=0.049)$, marginally insignificant for needles $(N=21, r=0.41, P=0.056)$, and insignificant for stems $(N=21, r=0.33, P=0.13)$. Absolute root, stem, needle, and total biomass did not change signifi-

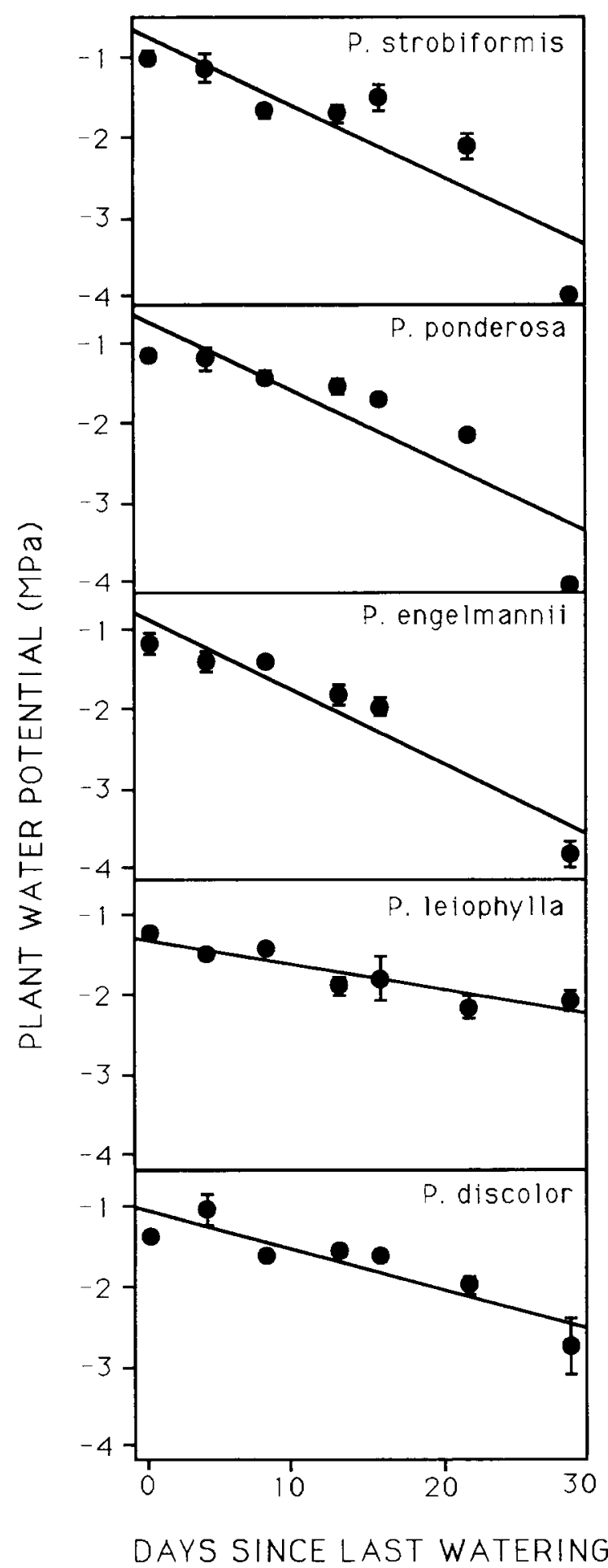

Fig. 5 (five panels). Mean plant water potential per seedling for five pine species over $29 \mathrm{~d}$ during which water was withheld. Bars are standard errors. Sample size is two for day 4 for $P$. discolor and three for all others. Although control plants (those receiving water) were measured on the 15 th day after water was withheld from treatment plants, these data are given as day 0 (i.e., 0 days of drying). Statistical results are given in Table 1. Elevational position of species increases from lower to upper frames. 
cantly for any of the species during the drought (regressions, $P>0.10$ ).

When we used all plants harvested in the gas exchange experiment regardless of sampling date, the five species differed significantly in biomass allocation to roots, stems, and needles (Fig. 7). At the extreme, P. leiophylla allocated $32 \%$ to roots, $10 \%$ to stems, and $58 \%$ to needles, whereas $P$. strobiformis allocated $47 \%$ to roots, $16 \%$ to stems, and $37 \%$ to needles. Greater drought resistance was not related to greater allocation to roots and smaller allocation to needles. In fact, the three most drought-resistant species (P. discolor, $P$. leiophylla, $P$. engelmannii) seemed to allocate less to roots and more to needles than did the other two species ( $P$. ponderosa, $P$. strobiformis). Differences among species in allocation followed this pattern when biomass investment was expressed as the ratio of organs involved in gas exchange and water loss to organs involved in water absorption (shoot: root or needles: root, $P>$ 0.10 ). The five species also differed significantly in absolute root mass and total plant mass, but again these differences were unrelated to relative drought resistance.

Within species, neither biomass allocation nor total biomass seemed important in determining success during the drought. Neither an individual's allocation to roots nor its total biomass was significantly related to its $\mathrm{CO}_{2}$ uptake nor to its maintenance of internal water potential during the drought within any of the five species (Table 2). In fact, for $P$. leiophylla, smaller plants actually maintained more favorable internal water potential and soil moisture conditions, probably because the plants did not substantially deplete water in deeper soil. Because this result may be an artifact of the confined water environment of individuals, this experiment does not adequately test the hypothesis that, within species, large root systems confer an advantage in drought resistance; in the field, plants with larger root systems may have access to water in a larger volume of soil at greater depth.

\section{DISCUSSION}

Drought resistance and elevational position-The results of this study suggest that drought resistance plays an important role in controlling the elevational positions of pine species in the Chiricahua Mountains. In response to an imposed greenhouse drought, seedlings of lower elevation species survived longer and under lower soil moisture levels than did higher elevation species. Furthermore, seedlings of lower elevation species exhibited less pronounced depression of net photosynthesis and plant water potential during drought.

The prominent exception to these conclusions was that $P$. leiophylla died at relatively high soil moisture levels, characteristic of higher elevation species, in contrast to its long survival time during the drought. Compared with those of the other pines, seedlings of $P$. leiophylla were small and allocated little to roots. Thus, their roots were probably shallow, leaving more untapped, moist soil below their roots than did other species. This may have increased the apparent percentage soil moisture of $P$. leiophylla containers, even though the roots of these seedlings may have experienced a similar degree of soil drought to seedlings of the other species.

The data suggest that the five pine species fall into three

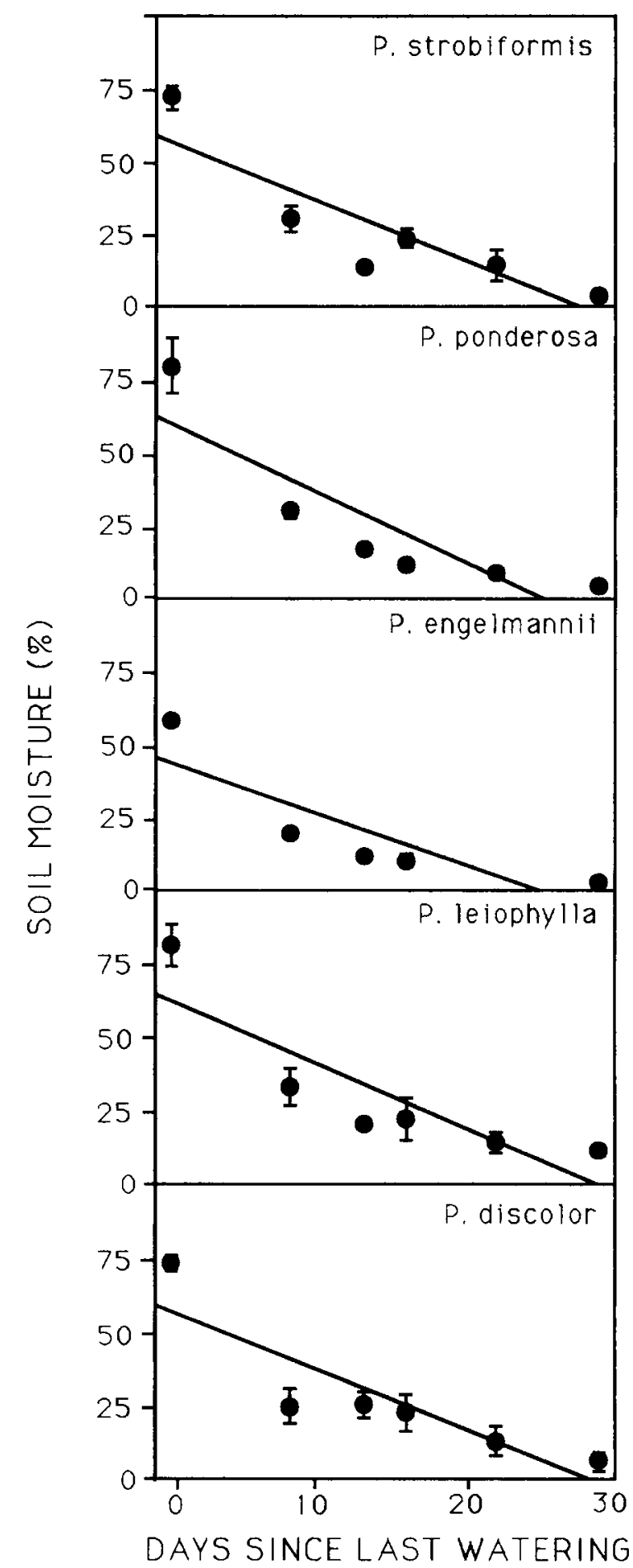

Fig. 6 (five panels). Mean percentage soil moisture per seedling pot for five pine species over $29 \mathrm{~d}$ during which water was withheld. Bars are standard errors. Sample size is three for each mean. There are no data for day 4. Although control plants (those receiving water) were measured on the 15 th day after water was withheld from treatment plants, these data are given as day 0 (i.e., 0 days of drying). Statistical results are given in Table 1. Elevational position of species increases from lower to upper frames. 


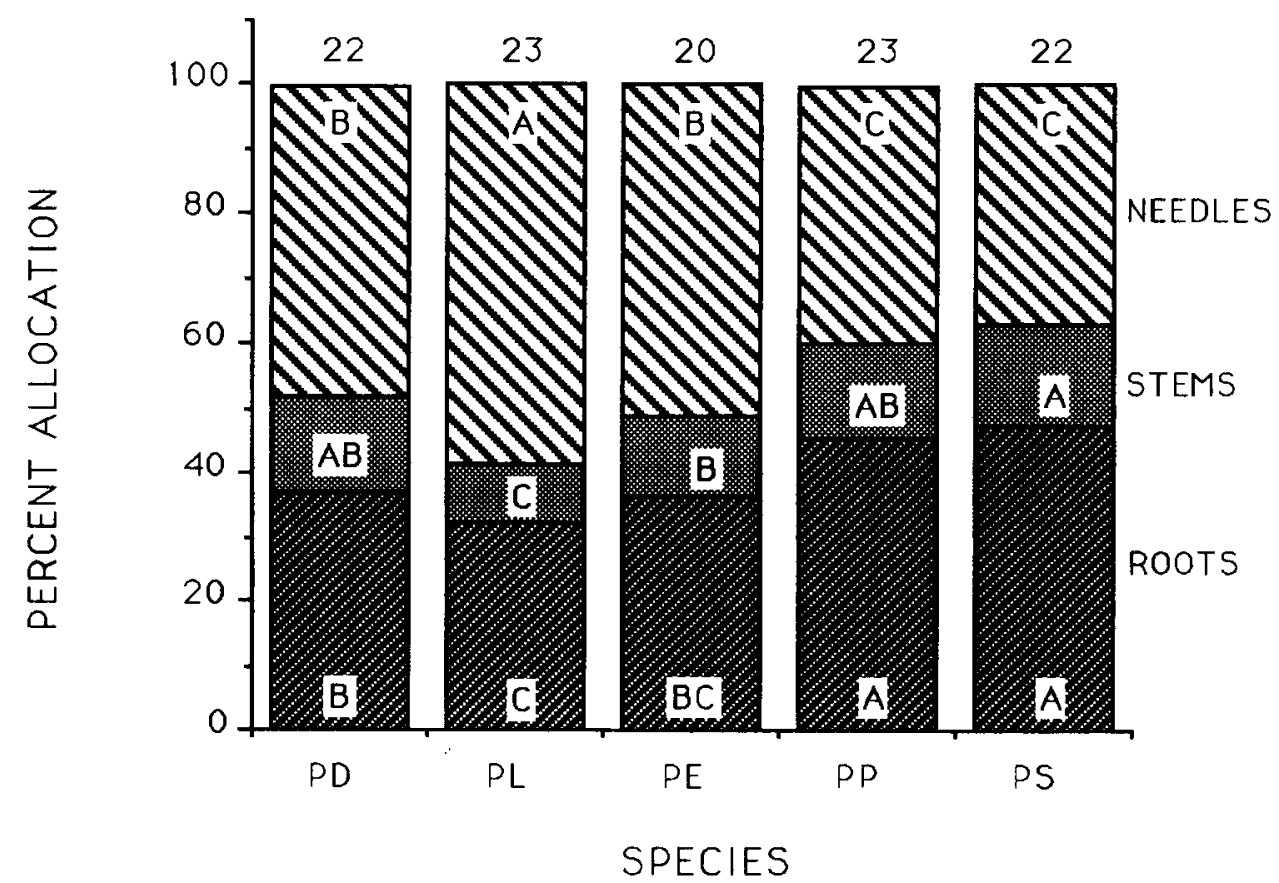

Fig. 7. Mean percentage biomass allocation to roots, stems, and needles for five pine species from the gas exchange experiment. Sample sizes are given at the top of the bars. Mean allocation differs significantly by the Kruskal-Wallis test for roots $(\mathrm{df}=4, \mathrm{H}=50.97, P<0.0001)$, stems (df $=4, \mathrm{H}=29.864, P<0.001)$, and needles $(\mathrm{df}=4, \mathrm{H}=76.75, P<0.0001$ ). Among species (within plant part category), means that do not share the same letter are significantly different $(P<0.05, \mathrm{C}$ method; Day and Quinn, 1989). $\mathrm{PD}=P$. discolor; $\mathrm{PL}=P$. leiophylla; $\mathrm{PE}=P$. engelmannii; $\mathrm{PP}=P$. ponderosa; $\mathrm{PS}=P$. strobiformis. Elevational position increases from left to right.

groups in regards to drought resistance. Most resistant is $P$. discolor, the lowest elevation species, which exhibited the best survival and the least reduction in gas exchange and water potential during drought. Next is $P$. leiophylla, the second lowest elevation species, whose response to drought was similar to that of $P$. discolor, differing mainly in its poorer survival. Finally, the three highest elevation species responded similarly, although $P$. engelmannii survived under lower soil moisture levels than did the other two species during the imposed drought. The similarity of responses of the two highest elevation species, $P$. ponderosa and $P$. strobiformis, is not surprising, for their distributions in the Chiricahua Mountains are more similar than the distributions of any other two pine species. Although $P$. strobiformis extends into higher elevations and more mesic sites, its lower elevation limit is only slightly above that of $P$. ponderos $a$. These drought resistance rankings hold whether survival or gas exchange response is used.

Most other experimental work has also supported the view that water stress and drought resistance control lower elevation limits of trees in western U.S. mountains (Pearson, 1931; Daubenmire, 1943a; Wright, 1968, 1970; Bunce, Chabot, and Miller, 1979; Barnes and Cunningham, 1987). We should point out, however, that only few studies have tested factors alternative to moisture availability that also correlate with the elevational gradient. Tolerance of high temperature (Wright, 1968), fire (Barton, 1991), deep litter under nurse trees (Barton, in press), and competition (Daubenmire, 1943b; Yeaton, 1981) are hypothesized to limit plant distributions over elevational gradients in desert mountain ranges but have rarely been tested.
Mechanisms of drought resistance-Despite the long history of experimental work on drought resistance and plant elevational positions, this study is the first to connect this relationship to mechanisms involving maintenance of water potential and $\mathrm{CO}_{2}$ uptake and to attempt to relate these mechanisms to plant traits. Tree seedlings resist drought by two major types of mechanisms (Heth and Kramer, 1975). They can tolerate drought by maintaining physiological activity and surviving despite internal dehydration (e.g., Jackson and Spomer, 1979; Barnes and Cunningham, 1987), or they can avoid drought by maintaining high tissue water status, either by enhancing water absorption (e.g., Kozlowski, 1949; Heth and Kramer, 1975) or by reducing water loss (e.g., Lopushinsky and Klock, 1974; Withers, 1978).

The data of this study do not provide conclusive evidence for the importance of differences among species in tolerance of internal dehydration. The lowest elevation species, $P$. discolor, exhibited relatively limited decrease in $\mathrm{CO}_{2}$ uptake as plant water potential dropped, but overall differences among the five species were not significant, a fact suggesting that tolerance mechanisms were unimportant. However, since the water potentials of the two most resistant species did not drop to the very low levels of the three other species, we could not compare effects of very low water potential levels on $\mathrm{CO}_{2}$ uptake, effects that could be of great importance in long-term drought resistance (Bunce, Chabot, and Miller, 1979).

Drought avoidance seems central to differences in drought resistance among the five pine species studied here. The two lowest elevation and most drought-resistant species were far superior to the other three species in maintaining water potential under drought. During the 
TABLE 2. Influence of days since last watering, percent biomass allocation to roots, and total plant biomass on $\mathrm{CO}_{2}$ uptake, plant water potential, and percent soil moisture in seedlings of five pine species. Values are $r^{2}$ from multiple regressions for each species analyzed separately

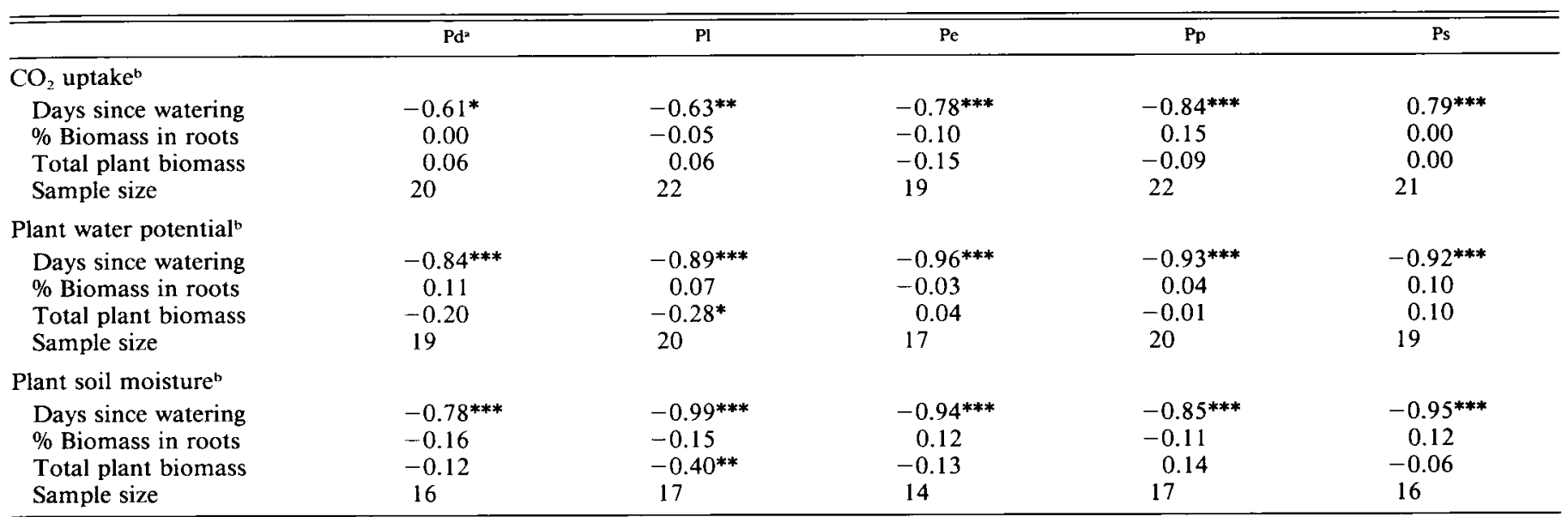

${ }^{\text {a }} \mathrm{Pd}=P$. discolor $; \mathrm{Pl}=P$. leiophylla $; \mathrm{Pe}=P$. engelmannii $; \mathrm{Pp}=P$. ponderosa $; \mathrm{Ps}=P$. strobiformis.

- To meet the assumptions of parametric analyses, the following transformed variables were used: $\log \left(\mathrm{CO}_{2}\right.$ uptake), $\log$ (water potential), square root (percent soil moisture), $\log$ (total plant biomass), and arc sin (percent allocation to roots).

${ }^{*} P<0.05$; ${ }^{* *} P<0.01 ;{ }^{* * *} P<0.001$; otherwise, $P>0.05$.

last week of the drought treatment, the three upper elevation species suffered collapses in plant water potential, whereas the two lower elevation species maintained much more favorable water potentials.

Several authors have hypothesized that great allocation of biomass to roots is a primary mechanism by which plants can avoid drought (e.g., Daubenmire, 1972; Tilman, 1988), by increasing water absorption and/or by decreasing transpiring surfaces relative to total mass. Studies have shown that this allocation pattern can be achieved through plastic responses (e.g., Racine, 1971; Comeau and Kimmins, 1989) or through intrinsically high root : shoot ratios (Larcher, 1980; Levitt, 1980). In regards to plastic responses, only $P$. discolor, the lowest elevation and most drought-resistant species, increased allocation to roots as the imposed drought ensued. Given the small shift in allocation, other mechanisms of drought resistance probably allowed seedlings of this species to maintain physiological activity in the face of drought and to allocate biomass according to new needs, which may have further enhanced the species' ability to resist stress (see Jordan and Miller, 1980).

Allocation to roots was not greater in more droughtresistant species. In fact, two of the least drought-resistant species showed significantly greater allocation to roots and less allocation to needles than did the other three species. The same trend was found in two other studies of seedlings of North American pines (Shirley, 1945; Strauss and Ledig, 1985). However, of the four Mexican pine species studied by Vargas-Hernandez, Orozco, and Keyes (1986), the most drought-resistant allocated significantly more to roots than did the others. Studies of species other than pines show a similar lack of consistency, whether plants are greenhouse-grown seedlings (Bourdeau, 1954; Satoo, 1956; Racine, 1971; Pereira and Kozlowski, 1976; Withers, 1978) or in situ harvests of plants of all ages (Bray, 1963; Barbour, 1973; Kummerow, 1980).

It is perhaps not surprising that biomass allocation and drought resistance often do not correlate among species along soil moisture gradients. A wide array of morphological and physiological traits, in addition to gross biomass allocation, can confer relative drought resistance in plants (Levitt, 1980; Kramer, 1983; Caldwell and Richards, 1986), making strict causal connections between drought resistance and biomass allocation unlikely. In addition, factors correlated with moisture gradients, such as fire (Harmon, Bratton, and White, 1983; Barton, in press) and herbivory (Oksanen et al., 1981), may exert selection pressure on allocation that conflicts with selection pressure from water stress.

That more resistant species tended to allocate less biomass to roots suggests that these species maintained favorable water potential primarily by limiting water loss and not by enhancing water absorption. However, gross biomass allocation is only one of many mechanisms that can enhance water absorption (Caldwell and Richards, 1986), and the experiments performed here were not designed to separate mechanisms of control of water absorption from those of reduction of water loss.

By whatever mechanism (e.g., thick cuticle, few stomata), superior ability to maintain water potential evidently allowed $P$. discolor, and to a lesser extent $P$. leiophylla, to maintain photosynthetic activity at much higher levels than the other three species were able to during the last 2 weeks of the imposed drought. One could thus argue that the relative drought resistance of these species depends on ability to maintain favorable leaf carbon balance, as Chabot and Bunce (1979) concluded for plants along a similar elevational gradient in Arizona. There is also a close correspondence in time, however, between the precipitous water potential loss in the three upper elevation species (22-29 d) and the mortality in these species (mean of about $31 \mathrm{~d}$ ). The two lower elevation species did not experience this water potential drop and survived much longer. Differences among the species in survival, therefore, evidently resulted more from shortterm, catastrophic effects of water potential loss than from maintenance of leaf carbon balance. 
Application of greenhouse results to field conditionsConcern is often expressed over the relevance of greenhouse studies, in which plants grow under conditions very different from those of the field, to patterns found in nature (e.g., Harper, 1977). We attempted to mitigate this concern by designing our experiments to mimic natural patterns of drought and pine seedling establishment encountered at sites where lower elevation pines occur (i.e., 1,500-1,800 m). In the Chiricahua Mountains, the bulk of pine seedlings emerge during the July-September monsoon season, encounter sporadic winter rains, and face a severe early summer drought at a still small, and vulnerable, size. This pattern of gradual and monotonic soil drying faced by small but not newly germinated seedlings was simulated in the greenhouse experiment by subjecting seedlings grown for $3 \frac{1 / 2}{2}$ mo to gradual soil drying.

Two results suggest that this simulation approximated field soil moisture conditions. First, soil water potential during the height of the drought in the field can reach below $-3 \mathrm{MPa}$ at elevations at which the lower two pine species occur (Barton, 1991) and at similar low elevations in other southwestern mountains (Wright, 1966). On the final day of the gas exchange sampling in the greenhouse experiment, the water potential of the still-photosynthesizing $P$. discolor and $P$. leiophylla averaged between -2 and $-2.5 \mathrm{MPa}$. Given that the percentage soil moisture of the five species did not differ on this day and that soil water potential is almost always greater (i.e., drier) than plant water potential, seedlings were most likely subjected to soil water potentials between -2 and $-3 \mathrm{MPa}$, well within the natural range of drought in the field. Second, the number of days for which seedlings survived during the imposed drought (maximum ranging from $60 \mathrm{~d}$ in the lowest elevation species to $36 \mathrm{~d}$ in the next-to-highest elevation species) seems to match reasonably well conditions in the Chiricahua Mountains, where completely rainless periods in April-June commonly last from about 4 to $6 \mathrm{wk}$.

Some aspects of the experiment clearly did not match field conditions. For example, the roots of some individuals of species with large seedlings (e.g., the lowest and the highest elevations species, $P$. discolor and $P$. strobiformis, respectively) struck the bottom of their containers, constraining their penetration and possibly hindering the expression of species differences in rooting depth, a trait possibly crucial in drought resistance in the field. Furthermore, species differences in the use of mycorrhizae, which may strongly influence water use and drought resistance, were not considered in the experiment. Nevertheless, the experiment seemed to do a good job of revealing differences among the five species in most of the morphological and physiological responses necessary for persisting through droughts encountered by pine seedlings attempting to establish at lower elevations in these mountains.

Several results from field studies of the three lower elevation pines in the Chiricahua Mountains (Barton, in press) support the conclusions drawn above from the greenhouse experiment. First, the mean elevational positions of the three species differed significantly in mean soil moisture, and in the expected order. Second, the abundance of all three species and the survival of juveniles of two of the species correlated significantly with soil mois- ture availability. Third, with decreasing elevation and thus soil moisture, seedlings of two of the three species tended to occur in microsites that seemed to provide higher soil moisture than did random microsites at the same elevation. Finally, for all species, hand-sown seeds germinated with the summer rains in experimental plots below their respective lower limits, but all resulting seedlings died by the end of the following May-June drought. In contrast, identically grown seedlings of all three species were still alive in higher elevation experimental plots after nearly 2 yr. Therefore, the greenhouse experiment, in combination with these field results, suggests that the lower limits of pine species in the Chiricahua Mountains are largely determined by the relative ability of young seedlings to survive their first and subsequent droughts by maintaining internal water potential.

\section{LITERATURE CITED}

Bailey, D. K., and F. G. Hawksworth. 1983. Pinaceae of the Chihuahuan Desert Region. Phytologia 53: 226-234.

Barbour, M. G. 1973. Desert dogma reexamined: root/shoot productivity and plant spacing. American Midland Naturalist 89: 4157.

Barnes, F. J., AND G. L. CUnNingham. 1987. Water relations and productivity in pinyon-juniper habitat types. In R. L. Everett [ed.], Proceedings: pinyon-juniper conference, 406-411. U.S. Department of Agriculture Forest Service General Technical Report INT 215. Ogden, UT.

BARTON, A. M. 1991. Factors controlling the elevational positions of pines in the Chiricahua Mountains, southeast Arizona: drought, competition, and fire. Ph.D. dissertation, University of Michigan. Ann Arbor, MI.

- In press. Factors controlling plant distributions: drought, competition, and fire in montane pines in the southwest USA. Ecological Monographs.

BOURDEAU, P. 1954. Oak seedling ecology determining segregation of species in Piedmont oak-hickory forests. Ecological Monographs 24: $297-320$.

BRAY, J. R. 1963. Root production and the estimation of net productivity. Canadian Journal of Botany 41: 65-72.

Bunce, J. A., B. F. Chabot, AND L. N. Miller. 1979. Role of annual leaf carbon balance in the distribution of plant species along an elevational gradient. Botanical Gazette 140: 288-294.

CALDWEll, M. M., AND J. H. RichaRdS. 1986. Competing root systems: morphology and models of absorption. In T. Givnish [ed.], The economy of plant form and function, 251-273. Cambridge University Press, Cambridge.

Chabot, B. F., AND J. A. BunCE. 1979. Drought-stress effects on leaf carbon balance. In O. T. Solbrig, S. Jain, G. B. Johnson, and P. H. Raven [eds.], Topics in plant population biology, 338-355. Columbia University Press, New York, NY.

Comeau, P. G., AND J. P. Kimmins. 1989. Above- and below-ground biomass and production of lodgepole pine on sites with different soil moisture regimes. Canadian Journal of Forest Research 19: $447-454$.

Critchfield, W. B., AND E. L. Litrle, JR. 1966. Geographic distribution of the pines of the world. U.S. Department of Agriculture Forest Service Miscellaneous Publication 991. U.S. Government Printing Office, Washington, DC.

DAUBenMiRe, R. F. 1943a. Soil temperature versus drouth as a factor determining lower altitudinal limits of trees in the Rocky Mountains. Botanical Gazette 105: 1-13.

- 1943b. Vegetation zonation in the Rocky Mountains. Botanical Review 9: 325-393.

- 1972. Plants and environment: a textbook of plant autecology. John Wiley and Sons, New York, NY.

DAY, R. W., AND G. P. QUINN. 1989. Comparisons of treatments after analysis of variance in ecology. Ecological Monographs 59: 433463. 
Drewes, H., and F. E. Williams. 1973. Mineral resources of the Chiricahua Wilderness Area, Cochise County, Arizona. U.S. Department of the Interior Geological Survey Bulletin 1385-A. U.S. Government Printing Office, Washington, DC.

Fenneman, N. M. 1931. Physiography of the western United States. McGraw-Hill, New York, NY.

Grime, J. P. 1979. Plant strategies and vegetation processes. John Wiley and Sons, Chichester, U.K.

Harmon, M. E., S. P. Bratton, ANd P. S. White. 1983. Disturbance and vegetation response in relation to environmental gradients in the Great Smoky Mountains. Vegetatio 55: 129-139.

HARPER, J. L. 1977. The population biology of plants. Academic Press, London.

Heth, D., AND P. J. Kramer. 1975. Drought tolerance of pine seedlings under various climatic conditions. Forest Science 21: 72-82.

JACKSON, P. A., AND G. G. SPOMER. 1979. Biophysical adaptations of four western conifers to habitat water conditions. Botanical Gazette 140: 428-432.

JORDAN, W. R., AND F. R. MILLER. 1980. Genetic variability in sorghum root systems: implications for drought tolerance. In N. C. Turner and P. J. Kramer [eds.], Adaptation of plants to water and high temperature stress, 383-399. John Wiley and Sons, New York, NY.

KozLowsKI, T. T. 1949. Light and water in relation to growth and competition of Piedmont trees. Ecological Monographs 19: 207231.

Kramer, P. J. 1983. Water relations of plants. Academic Press, Orlando, FL.

Kummerow, J. 1980. Adaptation of roots in water-stressed native vegetation. In N. C. Turner and P. J. Kramer [eds.], Adaptations of plants to water and high temperature stress, 57-73. John Wiley and Sons, New York, NY.

LARCher, W. 1980. Physiological plant ecology. Springer-Verlag, Berlin.

LEVITT, J. 1980. Responses of plants to environmental stresses, vol. 2, Water, radiation, salt, and other stresses. Academic Press, New York, NY.

LopUSHINSKY, W., AND G. O. KLOCK. 1974. Transpiration of conifer seedlings in relation to soil water potential. Forest Science 20: 181 186.

MARJANIEMI, D. K. 1969. Geologic history of an ash-flow sequence and its source area in the Basin and Range Province of southeastern Arizona. Ph.D. dissertation, University of Arizona. Tucson, AZ.

MARTIN, W. P., AND J. E. Fletcher. 1943. Vertical zonation of great soil groups on Mt. Graham, Arizona as correlated with climate, vegetation and profile characteristics. Arizona Agricultural Experiment Station Technical Bulletin 99. Tucson, AZ.

Oksanen, L., S. D. Fretwell, J. Arrud, and P. Neimala. 1981. Exploitation ecosystems in gradients of primary productivity. American Naturalist 118: 240-261.

Pearson, G. A. 1931. Forest types in the southwest as determined by climate and soil. U.S. Department of Agriculture Technical Bulletin 247, U.S. Government Printing Office, Washington, DC.

Peloquin, R. L., JR. 1971. Variation and hybridization patterns in Pinus ponderosa and Pinus engelmannii. Ph.D. dissertation, University of California. Santa Barbara, CA.
Pereira, J. S., and T. T. Kozlowski. 1976. Leaf anatomy and water relations of Eucalyptus camaldulensis and E. globulus seedlings. Canadian Journal of Botany 54: 2868-2880.

RACINE, C. H. 1971. Reproduction of three species of oak in relation to vegetational and environmental gradients in the southern Blue Ridge. Bulletin of the Torrey Botanical Club 98: 297-310.

SATOO, T. 1956. Drought resistance of some conifers at the first summer after their emergence. Tokyo University Forestry Bulletin 51: 1-108.

Sellers, W. D., R. H. Hill, and M. Sanderson-Rae. 1985. Arizona climate. University of Arizona Press, Tucson, AZ.

ShIRLEY, H. L. 1945. Reproduction of upland conifers in the Lake States as affected by root competition and light. American Midland Naturalist 33: 537-612.

SHREVE, F. 1915. The vegetation of a desert mountain range as conditioned by climatic factors. Publication No. 217, Carnegie Institution of Washington, Washington, DC.

SMITH, T., AND M. Huston. 1989. A theory of the spatial and temporal dynamics of plant communities. Vegetatio 83: 49-70.

Strauss, S. H., AND F. T. Ledig. 1985. Seedling architecture and life history evolution in pines. American Naturalist 125: 702-713.

Tilman, D. 1988. Plant strategies and the dynamics and structure of plant communities. Monographs in population biology No. 26. Princeton University Press, Princeton, NJ.

Vargas-Hernandez, J., A. M. Orozco, ANd M. R. Keyes. 1986. Drought response in seedlings of four Pinus species from central Mexico. In C. G. Taver and T. C. Hennessey [eds.], Physiological and genetic basis of forest decline, 158-165. Proceedings of the Ninth North American Forest Biology Workshop, Stillwater, OK.

Wallmo, O.C. 1955. Vegetation of the Huachuca Mountains, Arizona. American Midland Naturalist 54: 466-480.

WENTWORTH, T. R. 1981 . Vegetation on limestone and granite in the Mule Mountains, Arizona. Ecology 62: 469-482.

WhitTAKer, R. H., AND W. A. NIERING. 1964. Vegetation of the Santa Catalina Mountains, Arizona: I. Ecological classification and distribution of species. Journal of the Arizona Academy of Science 3: 9-34.

-, AND - 1965. Vegetation of the Santa Catalina Mountains, Arizona: II. A gradient analysis of the south slope. Ecology 46: 429452.

WITHERS, J. R. 1978. Studies on the status of unburnt Eucalyptus woodland at Ocean Grove, Victoria. III. Comparative water relations of the major tree species. Australian Journal of Botany 26: 819-835.

WRIGHT, R. D. 1966. Lower elevational limits of montane trees. I. Vegetational and environmental survey in the San Bernardino Mountains of California. Botanical Gazette 127: 184-193.

- 1968. Lower elevational limits of montane trees. II. Environment-keyed responses of three conifer species. Botanical Gazette 129: 219-226.

- 1970. $\mathrm{CO}_{2}$ exchange of seedling pines in the laboratory as related to lower elevational limits. American Midland Naturalist 83: 291-300.

Yeaton, R. I. 1981. Seedling characteristics and elevational distributions of pines (Pinaceae) in the Sierra Nevada of central California: a hypothesis. Madrono 28: 67-77. 